\title{
Microbubble-mediated delivery of human adenoviruses does not elicit innate and adaptive immunity response in an immunocompetent mouse model of prostate cancer
}

Flavia De Carlo ${ }^{1,2,3}$, Litty Thomas ${ }^{1,2,3}$, Bell Brooke ${ }^{1,2,3}$, Elliot T. Varney ${ }^{4}$, Rounak Nande ${ }^{5}$, Olivia Boskovic ${ }^{5}$, Gailen D. Marshall ${ }^{6}$, Pier Paolo Claudio ${ }^{1,2,3,7^{*}}$ (10 and Candace M. Howard ${ }^{4^{*}}$

\begin{abstract}
Background: Gene transfer to malignant sites using human adenoviruses (hAds) has been limited because of their immunogenic nature and host specificity. Murine cells often lack some of the receptors needed for hAds attachment, thus murine cells are generally non-permissive for human adenoviral infection and replication, which limits translational studies.

Methods: We have developed a gene transfer method that uses a combination of lipid-encapsulated perfluorocarbon microbubbles and ultrasound to protect and deliver hAds to a target tissue, bypassing the requirement of specific receptors.

Results: In an in vitro model, we showed that murine TRAMP-C2 and human DU145 prostate cancer cells display a comparable expression pattern of receptors involved in hAds adhesion and internalization. We also demonstrated that murine and human cells showed a dose-dependent increase in the percentage of cells transduced by hAd-GFP (green fluorescent protein) after $24 \mathrm{~h}$ and that GFP transgene was efficiently expressed at 48 and $72 \mathrm{~h}$ post-transduction. To assess if our image-guided delivery system could effectively protect the hAds from the immune system in vivo, we injected healthy immunocompetent mice (C57BL/6) or mice bearing a syngeneic prostate tumor (TRAMPC2) with hAd-GFP/MB complexes. Notably, we did not observe activation of innate (TNF-a and IL-6 cytokines), or adaptive immune response (neutralizing antibodies, INF- $\gamma+\mathrm{CD} 8^{+} \mathrm{T}$ cells).
\end{abstract}

Conclusions: This study brings us a step closer to demonstrating the feasibility of murine cancer models to investigate the clinical translation of image guided site-specific adenoviral gene therapy mediated by ultrasound-targeted microbubble destruction.

Keywords: Microbubbles, Gene transfer, Prostate cancer, Innate immunity, Adaptive immunity

\footnotetext{
*Correspondence: pclaudio@olemiss.edu; chowardclaudio@umc.edu

${ }^{4}$ Department of Radiology, University of Mississippi Medical Center, Jackson, MS 39126, USA

${ }^{7}$ Department of BioMolecular Sciences, Department of Radiation

Oncology, University of Mississippi, Jackson, MS 39126, USA

Full list of author information is available at the end of the article
}

(c) The Author(s) 2019. This article is distributed under the terms of the Creative Commons Attribution 4.0 International License (http://creativecommons.org/licenses/by/4.0/), which permits unrestricted use, distribution, and reproduction in any medium, provided you give appropriate credit to the original author(s) and the source, provide a link to the Creative Commons license, and indicate if changes were made. The Creative Commons Public Domain Dedication waiver (http://creativecommons.org/ publicdomain/zero/1.0/) applies to the data made available in this article, unless otherwise stated. 


\section{Background}

Human adenoviruses (hAds) are highly effective gene transfer agents that can introduce different types of genetic materials into cancer cells, including tumor suppressor genes [1]. Taxonomically grouped into the Adenoviridae family, adenoviruses are known to infect a wide variety of species [2]. Human adenoviruses are nonenveloped, icosahedral viruses, approximately $90 \mathrm{~nm}$ in diameter with a fiber complex known as knob domain that binds to the Coxsackie and Adenovirus Receptor (CAR), thus mediating cell tropism [3-5]. Interaction of adenoviral penton proteins with surface integrins such as $\alpha_{V} \beta_{3}$ and $\alpha_{v} \beta_{5}$ assists in the internalization of the virus; however, horizontal gene transfer of adenoviruses is often difficult due to the strict host specificity demonstrated by the viruses [6]. Generally, murine cells lack some of the receptors needed for hAd infection, such as CAR, thus making them generally non-permissive for hAd infection and replication. However, a very low level of hAd infection and replication has been described in some mouse cells $[7,8]$.

Human adenoviruses serotypes 2 and 5, classified under species type $C$, have shown promising results in treating locally advanced cancers, but these adenoviruses are highly immunogenic triggering both innate and adaptive immune responses $[3,4]$. The innate immune response is elicited in the professional antigen presenting cells (APC) by hAds through the myeloid differentiating factor 88 (MyD88)/Toll-like receptor (TLR)-9 dependent or independent pathways resulting in the up-regulation of type I interferons (IFNs) and inflammatory cytokines such as TNF- $\alpha$, IL- 6 and IL-12 $[9,10]$. Complement, another key component of the innate immunity, has an important role in the opsonization and clearance of adenoviruses. Complement activation can occur via direct binding of adenovirus with C3-derived fragments or through neutralizing antibodies produced after a previous immunization [11]. Viral exposure leads to innate and adaptive immune system interaction resulting in the differentiation of B cells into antibody-secreting plasma cells and the differentiation of $\mathrm{T}$ cells to cytotoxic $\mathrm{T}$ lymphocytes (CTLs). Anti-adenovirus 5 serotype antibodies have been found to target several components of the capsid, including hexons and fiber knobs, after both vaccination and natural infection to mediate virus neutralization $[2,12]$. Specifically, the humoral response causes a reduction in the viral load hampering the systemic re-administration of adenovirus in protocols of gene therapy [11]. While neutralizing antibodies (NAbs) prevent re-administration of the vector, the antigen-specific $\mathrm{T}$ cell response, mediated by CTLs, limits the duration of transgene expression and eliminates transduced cells. Therefore, the success of long-term gene therapy is dependent on the ability to avoid the induction of immune responses against both vector and the transgene product [13].

When adenoviruses are directly administrated via the circulatory system, $85-98 \%$ of the viral dose is accumulated in the liver within $30 \mathrm{~min}$, and the remaining is found in lung, kidney, and spleen resulting in off-target interactions and systemic toxicity $[2,14]$. Moreover, CAR is present in most human cell types that contribute to offtarget transduction or non-specific interactions $[2,6]$.

In humans, in the absence of pre-exiting immunity (rare in humans for Ad5 based vectors), the virus may bind blood clotting factors [15], IgM [16] and/or erythrocytes [17]. All this leads to rapid active RES (Kupffer cell) mediated capture and rapid clearance from the blood [18]. The sinusoidal endothelial spaces in the human liver measure $105 \mathrm{~nm}$ [19] i.e. smaller than the diameter of a virus with intact fibre domains, providing minimal hepatocyte access and infection, hence the minimal liver toxicity seen in the clinics compared to mice [20]. This is not recapitulated in mice as they do not have CAR on their erythrocytes and have a liver sinusoidal endothelial gap size of 130-160 nm depending on strain. Hence, RES capture but also very high levels of liver infection and toxicity are seen in mice.

In humans with pre-existing immunity neutralization and RES capture may be even more effective. Unfortunately, this is not recapitulated in research mice because they do not have pre-existing immunity, therefore in our studies we tried to circumvent this by injecting the mice two times with the hAds to simulate pre-existing immunity.

The aforementioned limitations have restricted the use of hAds for gene therapy to direct intratumoral (IT) or organ injection [21]. To overcome these limitations, we developed a systemic site-specific delivery system where ultrasound (US) contrast agents, here referred as microbubbles (MBs), are used as delivery vehicles. These hAds, loaded inside shells of acoustically active, lyophilized, lipid-encapsulated, perfluorocarbon filled MBs, are released when MBs are destroyed by US at the tumor site. These bubbles range between 2.5 and $4.5 \mu \mathrm{m}$, and after injection into the bloodstream, they can re-circulate through the vascular system numerous times for several minutes with minimal accumulation and interaction [2123]. Their small dimension prevents entrapment within the pulmonary capillary bed ( 5 to $8 \mu \mathrm{m})$, yet still enable proper protection of the viral vectors, such as hAds, from the environment [21]. MBs protect the viral payload from detection and rapid degradation by the hosts' immune system allowing for an intravenous (IV) inoculation rather than intratumoral (IT) injection [21, 24]. US breaks open the $\mathrm{MB} / \mathrm{hAds}$ complexes by inducing cavitation, allowing the hAds to transfer their transgene to the 
sonoporated region. Cavitation of the MBs causes small shockwaves, which increase cell permeability by forming temporary micropores on the cell surface, bypassing the receptor-mediated dependence of hAds cellular transduction.

In the recent past, we have successfully utilized this $\mathrm{MB}$ gene transfer system to selectively transfer both expression markers and therapeutic genes into tumors in immune deficient mice [21, 25-27]. In this study, we compared the transduction efficiency of hAd-GFP and GFP expression in the mouse prostate cancer cell line (TRAMP-C2, C57BL/6 background) and the human DU145 prostate cancer cell line. Additionally, using healthy immunocompetent C57BL/6 mice or mice bearing a syngeneic TRAMP-C2 prostate tumor, we evaluated the capability of ultrasound contrast agents to protect systemically-delivered adenoviral vectors from the innate and adaptive immune system using an in vivo model, and the contrast agent's ability to prevent off-target distribution utilizing ultrasound-targeted microbubble destruction.

\section{Materials and methods Cell lines}

The DU145 (human prostate adenocarcinoma, radioresistant, p53 deficient, derived from a brain metastasis), TRAMP-C2 (prostate adenocarcinoma, radio-resistant, wild-type p53, derived from 32-week old TRAMP mice) and human kidney embryonic HEK-293 cell lines were obtained from the American Type Culture Collection (ATCC, Rockville, MD). DU145 cells were grown in RPMI-1640 (Hyclone, Waltham, MA) supplemented with $10 \%$ fetal bovine serum (FBS) (Hyclone), and 100-units/ $\mathrm{ml}$ penicillin supplemented with $1 \mathrm{mg} / \mathrm{ml}$ streptomycin (Hyclone). TRAMP-C2 cells were grown in Dulbecco's modified Eagle's medium (Hyclone) supplemented with 5\% FBS (Hyclone), 5\% Nu-Serum IV (Corning, Corning, NY), $5 \mu \mathrm{g} / \mathrm{ml}$ bovine insulin (Sigma Aldrich, St. Louis, MO), $10 \mathrm{nM}$ dehydroisoandrosterone 90\% (Sigma Aldrich), and 100 units/ml penicillin supplemented with $1 \mathrm{mg} / \mathrm{ml}$ streptomycin (Hyclone). The HEK-293 cells were grown in Dulbecco's modified Eagle's medium (Hyclone) supplemented with 10\% FBS (Hyclone). All cells were grown at $37{ }^{\circ} \mathrm{C}$, in a $5 \% \mathrm{CO}_{2}$ in $95 \%$ atmosphere incubator.

\section{Adenoviral production}

Human adenovirus serotype 5 E1/E3 deleted, which expresses the GFP gene under the strong cytomegalovirus (CMV) constitutive promoter, was generated using the Ad Easy system (Agilent Technologies, Carlsbad,
$\mathrm{CA}$ ) then amplified and purified with the BD Adeno-X virus purification kit (BD Biosciences, Mountain View, CA) following manufacturer's directions. Viral titers were determined by Tissue Culture Infectious Dose 50 $\left(\mathrm{TCID}_{50}\right)$ and the titer was adjusted to $1 \times 10^{11}$ plaqueforming units (PFU)/ml as described. Each viral stock was propagated and purified from infected HEK-293 cells, as previously published [21, 25, 27-29]. HEK-293 cells were harvested $48 \mathrm{~h}$ after infection, pelleted and suspended in medium. Cells were lysed by a three-freeze/ thaw cycle method and cell debris were removed by centrifugation. Viruses were purified by chromatography followed by dialysis and stored at $-80^{\circ} \mathrm{C}$.

\section{Human adenovirus attachment receptors analysis}

DU145 and TRAMP-C2 cells were analyzed for the expression of hAd attachment receptors: CAR (coxsackie adenovirus receptor), $\alpha_{\mathrm{V}} \beta_{5}$ and $\alpha_{\mathrm{V}} \beta_{3}$ integrins. Single cells suspension was obtained and cells were labeled with the following antibodies in cold FACS buffer (PBS $1 \times$ + EDTA $2 \mathrm{mM}+$ FBS 0.5\%): Rabbit anti-human CAR Monoclonal antibody FITC-conjugated (10799-R271-F, Sino Biologicals Inc, Beijing, China), Rabbit Anti-Integrin $\alpha_{V}+\beta_{5}$ Polyclonal Antibody Alexa Fluor ${ }^{\circledR} 647$ Conjugated (bs-1356R-A647, Bioss, Woburn, MA) and Rabbit Anti-Integrin $\alpha_{V}+\beta_{3}(C D 51+C D 61)$ Polyclonal Antibody Alexa Fluor $^{\circledR} 488$ Conjugated (bs-1310R-A488, Bioss). Rabbit Isotype control antibodies were used for background normalization. Cells were incubated for $30 \mathrm{~min}$ at $4{ }^{\circ} \mathrm{C}$ in the dark, then washed twice in FACS buffer. Cells were stained with $2 \mu \mathrm{g} / \mathrm{ml}$ of propidium iodide for dead cell exclusion. Samples were acquired with a BD Accuri C6 Flow Cytometer (BD Biosciences, San Jose, CA) and data analyzed by the CFlow Plus Analysis Software (BD Biosciences).

\section{Transduction efficiency}

Adenoviral transduction efficiency was evaluated $24 \mathrm{~h}$ post-infection of mouse TRAMP-C2 and human DU145 cell lines with 10, 25, $50 \mathrm{MOI}$ of hAd-GFP, using DMEM media or RPMI-1640 media with $2 \%$ heat-inactivated FBS (Hyclone), respectively. A qualitative analysis of the transduction efficiency was performed acquiring images of hAdGFP infected cells by fluorescence microscopy using an inverted Olympus IX70 microscope (Olympus America, Inc. Melville, NY). Cells were counterstained with Hoechst 33342 (Molecular Probes, Eugene, OR). Additionally, the percentage of cells positive to GFP was measured 24-h postinfection of mouse TRAMP-C2 and human DU145 cell lines with 10, 25, 50 MOI of hAd-GFP by flow cytometry. Propidium iodide labeling was used to exclude dead cells. 


\section{GFP gene expression}

Transgene expression was assessed in TRAMP-C2 and human DU145 cell lines at 24, 48, and $72 \mathrm{~h}$ after infection with 10 MOI of hAds, using DMEM or RPMI-1640 media with 2\% heat-inactivated FBS (Hyclone), respectively. GFP median fluorescence intensity was measured by flow cytometry. Propidium iodide staining was used to exclude dead cells.

\section{Preparation of microbubbles}

Targeson, (Targeson, Inc. San Diego, CA) uniquely-constructed ultrasound contrast agents (perfluorocarbon microbubbles, encapsulated by a lipid monolayer and polyethylene glycol stabilizer), were prepared following manufacturer's instructions. MBs were reconstituted in the presence or absence of $1 \mathrm{ml}$ of $1 \times 10^{11}$ plaque-forming units $/ \mathrm{ml}$ of Ads and unenclosed, surface-associated Ads were inactivated, as previously described [21, 25, 27].

Briefly, unenclosed and free adenoviruses were inactivated by incubating 1 volume of microbubbles formed in the presence of Ad-GFP with 10 volumes of a solution containing $60 \mathrm{mg} / \mathrm{ml}$ of human complement (Sigma Aldrich, Saint Louis, MS) for $30 \mathrm{~min}$ at $37^{\circ} \mathrm{C}$. Microbubbles were then washed with $10 \mathrm{ml}$ of phosphate buffer saline solution (PBS). The milky white suspension floating on the top of PBS was then collected and used in the in vitro and in vivo experiments. We delivered $10^{9} \mathrm{PFU}$ Ad-GFP/mouse using the MBs/US system, and the titer was comparable to the one injected in the control mice (IV and IT injections) (see Additional file 1).

\section{In vivo ultrasound-targeted microbubble destruction}

Animal studies were performed in accordance with National Institutes of Health recommendations and the approval of the Institutional Animal Care and Use Committee. Animal care and humane use and treatment of mice were in strict compliance with (i) institutional guidelines, (ii) the Guide for the Care and Use of Laboratory Animals (National Academy of Sciences, Washington, DC, 1996), and (iii) the Association for Assessment and Accreditation of Laboratory Animal Care International (Rockville, MD, 1997). All the animals used in these studies were 8-11 week-old male C57BL/6 $\left(\mathrm{H}_{2}{ }^{\mathrm{b}}\right)$ immunocompetent mice (Jackson Laboratories, Bar Harbor, ME). Two in vivo experiments were performed using a total of 30 mice divided into groups containing 3-6 mice for each experiment. The first experiment was performed in healthy C57BL/6 mice while the second utilized C57BL/6 bearing a syngeneic TRAMP-C2 tumor. To establish syngeneic tumor grafts, the mice were injected in the right flank with TRAMP-C2 prostate adenocarcinoma cell lines $\left(5 \times 10^{6}\right.$ cancer cells $)$ using a 20 -gauge needle. Treatment was started when the tumor reached
$50-100 \mathrm{~mm}^{3}$ of volume. During the experimental procedure, the mice were sedated using an IMPAQ6 anesthesia apparatus (VetEquip, Pleasanton, CA) saturated with $3-5 \%$ isofluorane and $10-15 \%$ oxygen with the aid of a precision vaporizer (VetEquip), and placed on a warming mat set at $37^{\circ} \mathrm{C}$. Treatments were delivered intravenously (IV) or intratumorally (IT) in a volume of $100 \mu \mathrm{l}$ using a 30-gauge needle. US exposure was performed with a Micro-Maxx SonoSite ultrasound machine (SonoSite) equipped with the transducer L25 set at 0.7 Mechanical Index (MI), 1.8 MPa for $10 \mathrm{~min}$ [21, 25, 27].

\section{TNF- $a$ and IL- 6 quantification}

Two hours after the first IV or IT injection, mice were deeply sedated and $100 \mu \mathrm{l}$ of blood was collected by puncture of the mandibular vein using a Goldenrod Animal Lancet (Braintree Scientific, Inc., Braintree, MA). Mouse serum TNF- $\alpha$ and IL-6 levels were analyzed using Quantikine HS Mouse TNF-alpha (R\&D System, Minneapolis, MN) and Quantikine Mouse IL-6 and (R\&D System) Immunoassay solid-phase ELISAs, following manufacturer's directions.

\section{Anti-adenovirus antibodies detection}

At the experimental endpoints, mice were deeply anesthetized, and blood was collected from the heart. Afterwards, the mice were sacrificed by $\mathrm{CO}_{2}$ gas and cervical dislocation.

ELISA plates were coated overnight at $4{ }^{\circ} \mathrm{C}$ with $5 \times 10^{6} \mathrm{vp} /$ well of Ad-GFP. Plates were blocked for $2 \mathrm{~h}$ at room temperature with $3 \%$ BSA/PBS. Mice serum was heat inactivated at $56{ }^{\circ} \mathrm{C}$ for $30 \mathrm{~min}$, diluted 1:3000 in $1 \% \mathrm{BSA} / 0.05 \%$ Tween $20 / \mathrm{PBS}$, added to the wells in triplicate and incubated for $2 \mathrm{~h}$ at room temperature. Reactive antibodies were detected using a secondary antibody sheep anti-mouse IgG HRP-conjugated (NA931, GE Healthcare, Chicago, IL). SureBlue TMB Peroxidase Substrate (KPL, Gaithersburg, MD) was added to each well and color development was assessed at $650 \mathrm{~nm}$ using a microplate reader.

\section{INF- $\gamma$ ELISPOT}

Immediately following mice euthanasia, spleens were collected and processed. Red blood cells were removed using a Red Blood Cells Lysis buffer (Affymetrix, Santa Clara, CA). Splenocytes were suspended at $2 \times 10^{6}$ cells/ $\mathrm{ml}$ in AIM V medium containing L-glutamine, streptomycin sulfate $50 \mu \mathrm{g} / \mathrm{ml}$, and gentamicin sulfate $10 \mu \mathrm{g} / \mathrm{ml}$, and supplemented with $50 \mu \mathrm{M} 2$-mercaptoethanol. Two hundred-thousand cells/well were stimulated with $2 \mu \mathrm{g} /$ $\mathrm{ml}$ of DNA-binding protein peptide, corresponding to DBP $_{418-426}$ (FASLNAEDL, $\mathrm{H}-2 \mathrm{D}^{\mathrm{b}}$ restricted peptide, New England Peptide, Gardner, MA) [30] for $24 \mathrm{~h}$. Stimulation 
of splenocytes with $0.05 \mu \mathrm{g} / \mathrm{ml}$ of anti-mouse CD3 was used as positive control (552774, BD Biosciences, Franklin Lakes, NJ). Splenocytes were subjected to ELISpot assay using the INF- $\gamma$ ELISpot PLUS kit (Mabtech, Nacka Strand, Sweden) following manufacturer's directions. Spots, corresponding to INF- $\gamma$ secreting cells, were counted using a Zeiss ELISpot reader system (service provided by ZellNet, Inc. Fort Lee, NJ).

\section{Statistical analysis}

Statistical analysis was performed using GraphPad Prism 6 statistical software (Graphpad, Inc., La Jolla, CA). One and two-way analysis of variance (ANOVA) with Tukey or Bonferroni multiple comparisons post-test was used to determine the statistical significance of the differences between experimental groups. Multiple t-test was used for the ELISpot analysis. p-values of less than 0.05 were considered statistically significant.

\section{Results}

TRAMP-C2 and DU145 cells express $h A d$ receptors integrins $\alpha \mathrm{V} \beta 5, \alpha \mathrm{V} \beta 3$, and CAR

The expression profile of surface proteins known to be responsible for the specific attachment of hAd5 to human cells was evaluated by flow cytometry (Fig. 1a, b). Both human DU145 and mouse TRAMP-C2 prostate cancer cells were positive to the expression of integrin $\alpha_{\mathrm{V}} \beta_{5}$ and $\alpha_{V} \beta_{3}$. The percentage of cells expressing human Coxsackie and Adenovirus Receptor (CAR), as expected, was higher in the human cell line DU145 when compared to the mouse TRAMP C2 cells ( $97 \pm 0.9 \%$ vs. $62.9 \pm 1.5 \%$ ).

\begin{tabular}{|c|c|c|c|}
\hline Cell lines & hCAR & Integrin $\alpha \mathrm{V} \beta 3$ & Integrin $\alpha \mathrm{V} \beta 5$ \\
\hline TRAMP-C2 & $62.9 \% \pm 1.5$ & $3.5 \% \pm 1.4$ & $93.4 \% \pm 2.2$ \\
\hline DU145 & $97 \% \pm 0.9$ & $1.3 \% \pm 0.4$ & $87.8 \% \pm 1.1$ \\
\hline
\end{tabular}
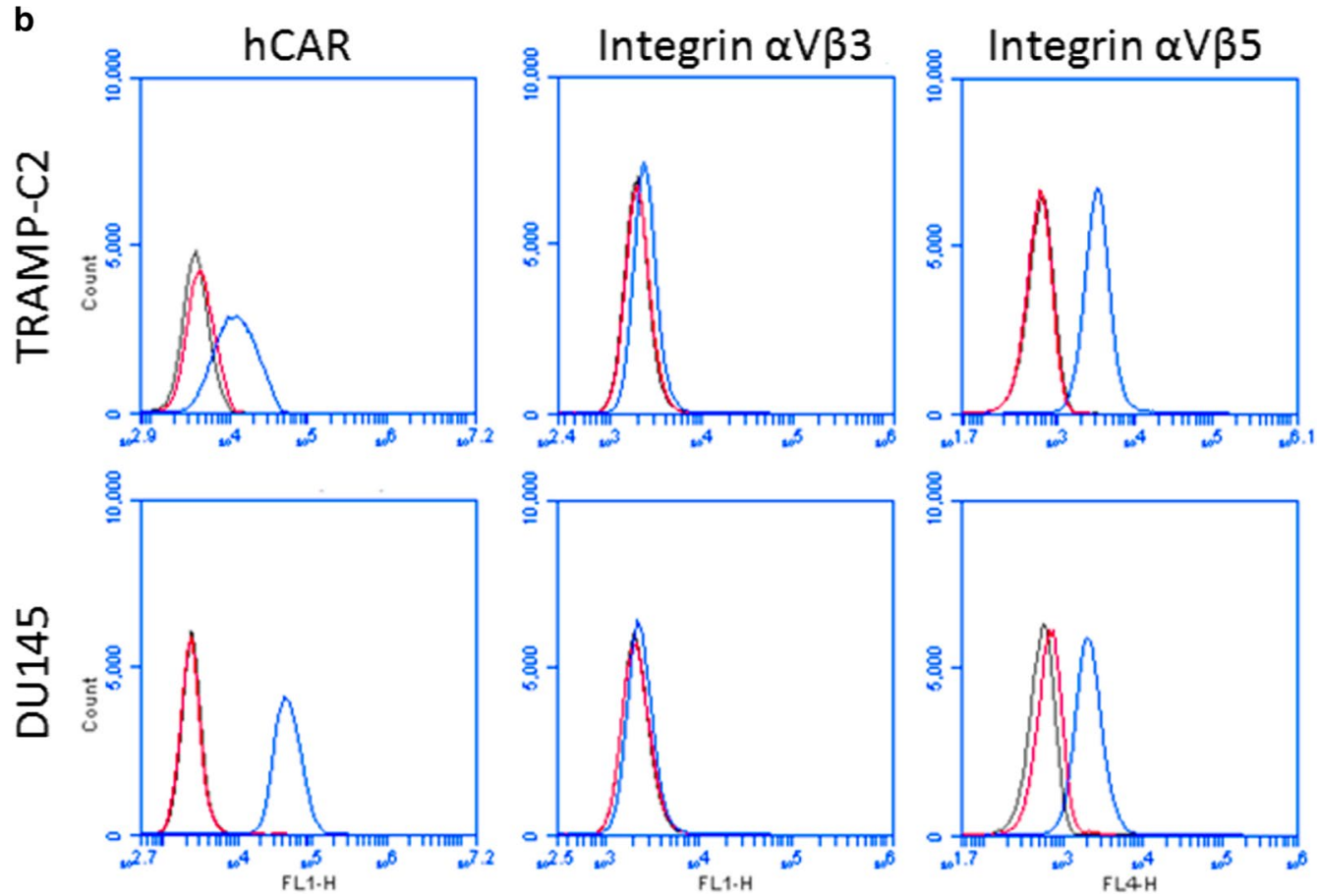

Fig. 1 Human adenoviral receptors expression in TRAMP-C2 and DU145. a TRAMP-C2 and DU145 cells were labeled with Rabbit Anti-human Coxsackie adenovirus receptor FITC conjugated (hCAR), Rabbit Anti-Integrin $a_{V}+\beta_{5}$ Alexa Fluor ${ }^{\circledR} 647$ Conjugated and Rabbit Anti-Integrin $a_{V}+\beta_{3}$ Alexa Fluor ${ }^{\circledR} 488$ Conjugated. Percentages are represented as mean \pm SEM of three biological repetitions. b Representative flow cytometer histograms showing the percentage of cells that are expressing human adenovirus receptors. Black: negative control, Red: isotype control, Blue: specific antibody 
TRAMP-C2 and DU145 cells are transduced by hAd-GFP Despite the high host specificity of adenovirus, we wanted to define if murine cells could be infected by a hAd. The transduction efficiency of murine TRAMP-C2 and human DU145 prostate cancer cell lines by hAdGFP was assessed $24 \mathrm{~h}$ post infection with 10,25 , and 50 MOI (multiplicity of infection) of hAd-GFP. Using fluorescence microscopy, we observed a dose-dependent increase of GFP positive cells in both TRAMP-C2 and DU145 cells (Fig. 2a). DU145 cells exhibited a higher level of transduction in comparison to TRAMP-C2 cells at each multiplicity of infection.

To quantify TRAMP-C2 and DU145 cells transduction with hAd-GFP at 10, 25, and $50 \mathrm{MOI}$, a flow cytometry analysis was performed $24 \mathrm{~h}$ post infection (Fig. $2 \mathrm{~b}$ ). An increase in the percentage of GFP positive cells was observed in both TRAMP-C2 and DU145 cells as the MOI was increased. However, when comparing similar treatments, TRAMP-C2 cells were significantly less affected than were DU145 as indicated by a GFP positive population of only $17.7 \pm 2.8 \%$ at $50 \mathrm{MOI}$ in TRAMP-C2 vs $59 \pm 1.5 \%$ in DU145.

\section{TRAMP-C2 and DU145 cells express GFP following transduction with hAd-GFP}

The hAds-GFP used in this study express the GFP gene under the strong (CMV) cytomegalovirus constitutive promoter. In order to assess if mouse TRAMP-C2 and human DU145 prostate cancer cells were able to express GFP after transduction with hAd-GFP, both cell lines were infected with $10 \mathrm{MOI}$ of hAds, and the median fluorescence intensity (MFI) was measured at 24, 48, and $72 \mathrm{~h}$ to determine the degree of GFP protein synthesis. We showed that the GFP transgene is expressed in both TRAMP-C2 (Fig. 3a) and DU145 (Fig. 3b) cell lines. When comparing human and murine cell lines, GFP

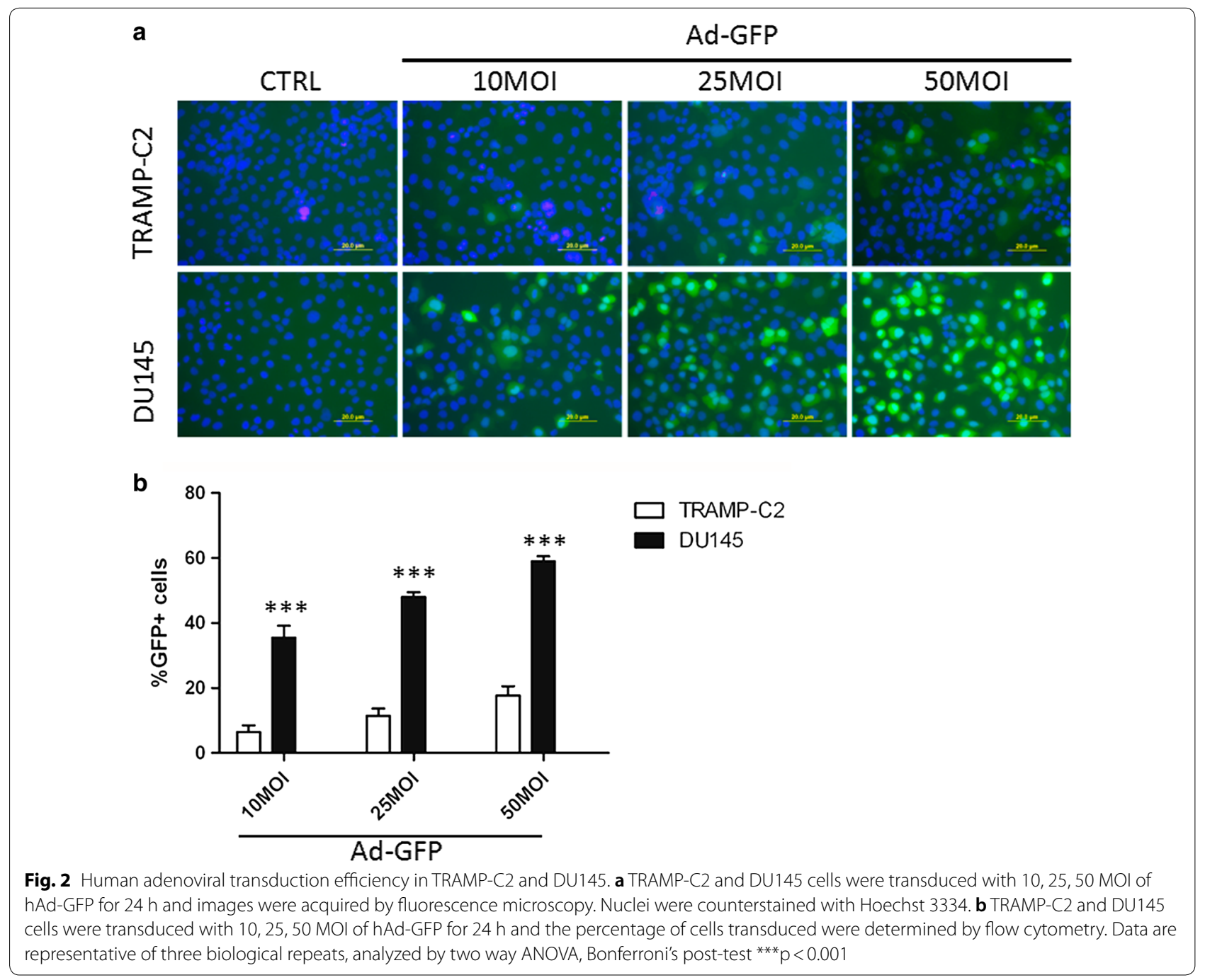


MFI in DU145 was higher than TRAMP-C2 at all 3 times points corresponding to a greater transduction efficiency of hAds in human cells. However, when GFP MFI was corrected by the percentage of $\mathrm{GFP}^{+}$cells detected at 24 , 48 and $72 \mathrm{~h}$, a similar GFP expression in both murine and human cells was observed (Fig. 3c).

\section{Microbubbles protect hAd-GFP from activation of the innate immune system}

The first barrier to viral infection is the innate immunity, which is comprised of cellular and soluble components including complement, immunoglobulin, erythrocyte and clotting factor binding (depending on species), and inflammatory cytokines (TNF- $\alpha$, IL-1 $\beta$, IL-6) [13]. To evaluate the MBs' ability to protect in immune competent animals the hAds from the innate immunity, the levels of serum inflammatory cytokines after IV and IT injection of both unprotected hAd-GFP and MB-protected hAdGFP were measured using immunoassay solid-phase ELISAs. The experimental design is shown in Fig. 4. Direct IV injection of unprotected hAd-GFP in healthy C57BL/6 immunocompetent mice (Fig. 4a, EXP.1) induces a marked increase in both TNF- $\alpha$ (Fig. 5a) and IL-6 (Fig. 5b) in comparison to control groups (saline and MBs only). As anticipated, the administration of MB-protected hAd-GFP completely shielded the adenovirus, preventing the activation of innate immunity in both ultrasound-treated and non-treated groups. When C57BL/6 mice bearing a syngeneic tumor were used (Fig. 4b, EXP.2), we detected an increase in both TNF- $\alpha$ (Fig. 5c) and IL-6 (Fig. 5d) in hAd-GFP IV injected mice just as we did using C57BL/6 mice without tumor; however, the increase in IL- 6 using hAd-GFP IV injected mice was less substantial than that of the $\mathrm{C} 57 \mathrm{BL} / 6$ mice without tumor. When C57BL/6 mice bearing tumors received an IT injection, the level of TNF- $\alpha$ was again comparable to the hAd-GFP IV group, but IL-6 production was absent. As expected, we observed that the administration of hAd-GFP/MBs complexes allows for the evasion of adenovirus from the innate immunity with or without the use of ultrasound.

\section{Microbubbles protect hAd-GFP from the activation of the humoral response}

The production of neutralizing antibodies specific for hAd-GFP (IgG anti-hAd) was evaluated using a direct ELISA assay. Blood was collected from the heart at the experimental endpoints of 2 months in C57BL/6 mice (Fig. 4a, EXP.1) and 1 month in C57BL/6 mice bearing a syngeneic tumor (Fig. 4b, EXP.2). There was a statistically higher titer of IgG anti-hAd when mice were injected intravenously with unprotected hAd-GFP. The production levels of neutralizing antibodies specific for

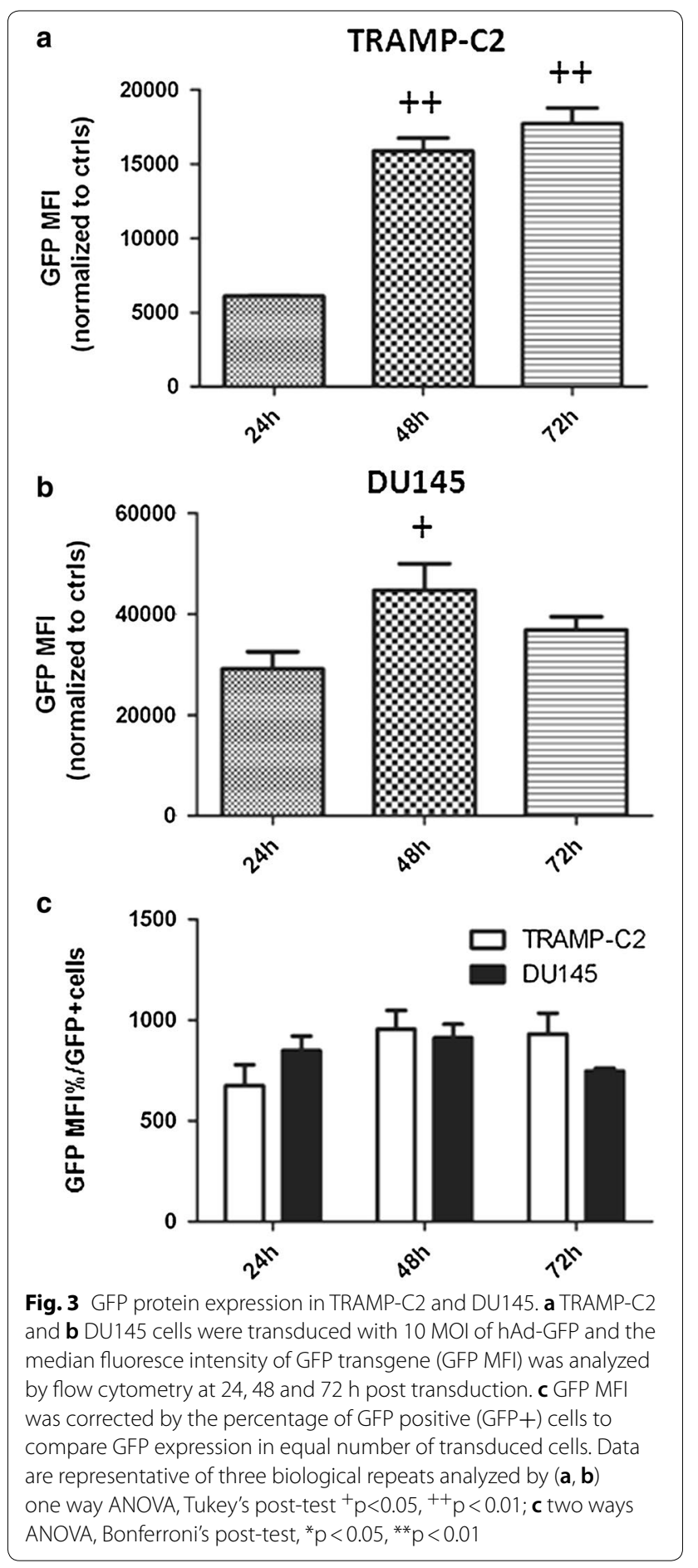

hAd-GFP nearly doubled when mice received two IV injections of unprotected hAd-GFP in EXP.1 (Fig. 6a). C57BL/6 mice from EXP.2 (Fig. 6b) that received an IT injection of hAd-GFP showed a lower increase in NAbs when compared to the IV injection groups. Not surprisingly, we observed that the administration of MBs/ 


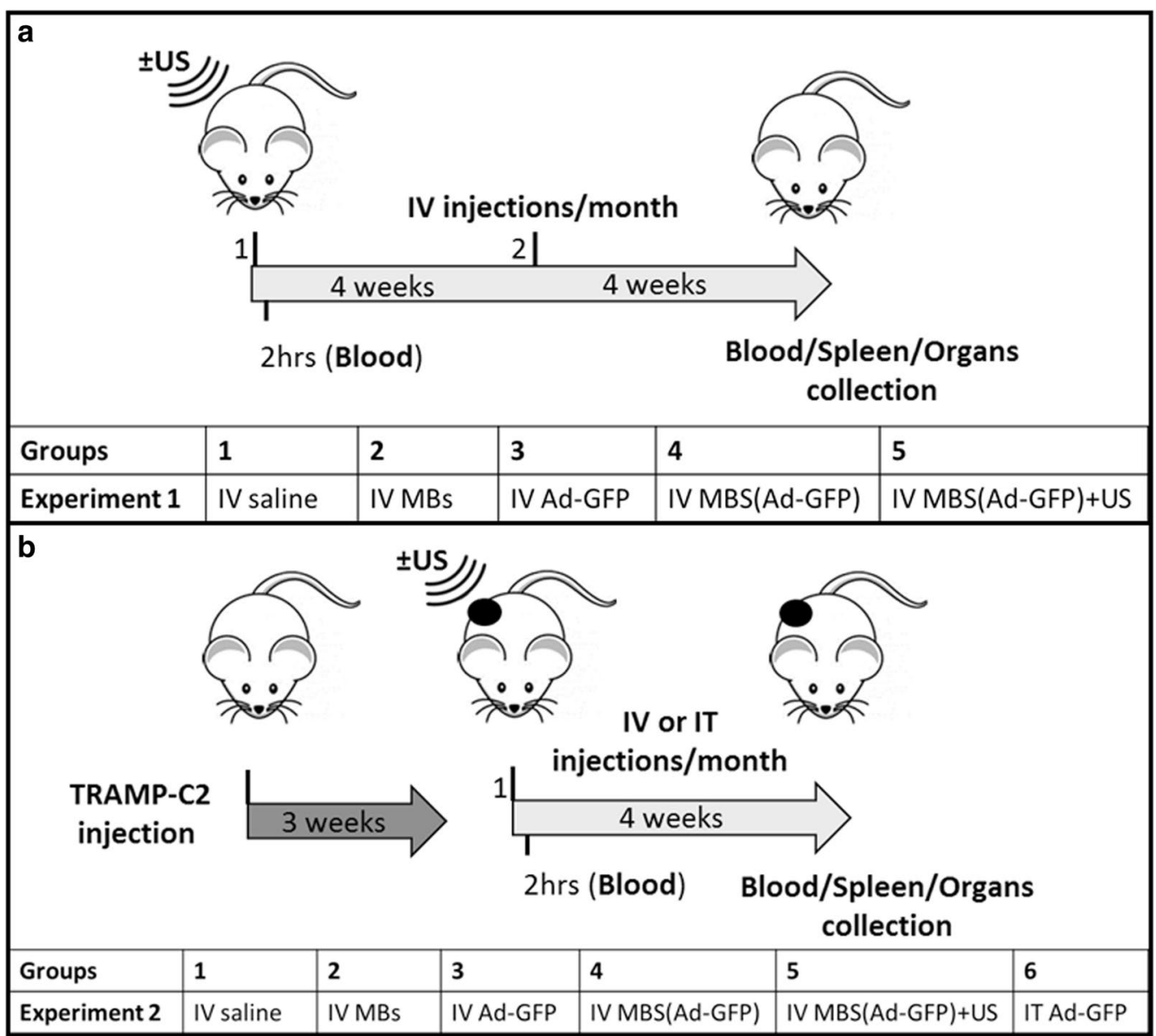

Fig. 4 In vivo experimental design. Two in vivo experiments were performed. a In experiment 1 we used healthy C57BL/6. Mice were injected IV with either saline, MBs, hAd-GFP, MBs(hAd-GFP), or MBs(hAd-GFP) + US. Blood samples were collected $2 \mathrm{~h}$ post-injection to determine inflammatory cytokine response. After 4 weeks, mice were re-injected and 4 weeks later, mice were sacrificed and blood and organs were collected. $\mathbf{b} \mathrm{In}$ experiment 2 we used C57BL/6 mice injected subcutaneously with $5 \times 10^{6}$ TRAMP-C2 cells. When syngeneic tumor grafts were established (approximately 3 weeks post-injection of cancer cells, and with tumor volumes between 50 and $100 \mathrm{~mm}^{3}$ ) mice were injected IV with either saline, MBs, hAd-GFP, MBs(hAd-GFP), MBs(hAd-GFP) + US, or via IT with hAd-GFP. Two hours after the treatment, blood samples were collected to determine inflammatory cytokine response. At the endpoint of 4 weeks, mice were sacrificed and blood and organs were collected. Activation of the innate and adaptive immune response were evaluated in both experiments by ELISA (TNF-a, IL-6 and NAbs)

hAd-GFP complexes \pm US completely prevented the activation of a humoral response in immune competent mice.

\section{Microbubbles protect hAd-GFP from the activation of the cellular response}

The presence of antigen-specific INF- $\gamma$ producing $C D 8^{+}$ $\mathrm{T}$ cells was assessed by stimulating the splenocytes ex vivo with $\mathrm{DBP}_{418-426}$ peptide. The number of cells responding to the stimulation was evaluated using an ELISpot assay. Splenocytes were collected at the experimental endpoints. A statistically higher amount of INF- $\gamma$ spot forming units were found in the stimulated splenocytes compared to the un-stimulated splenocytes in the
IV-injected, unprotected hAd-GFP mice. The number of INF- $\gamma$ spot forming units counted in samples from mice in EXP.1 (Fig. 7a, c) that received two IV injections of unprotected hAd-GFP was almost twofold of that which was observed in the mice from EXP.2 (Fig. 7b, d). Mice from EXP.2 (Fig. 7b) that received an IT injection of hAd-GFP showed a greater number of INF- $\gamma$ spot forming units when compared to the IV injections. Notably, we did not observe a statistically significant activation of splenocytes after stimulation with $\mathrm{DBP}_{418-426}$ in mice that received MBs/hAd-GFP complexes \pm US treatment indicating that the UMTD we developed prevented the activation of a humoral response in immune competent mice. 

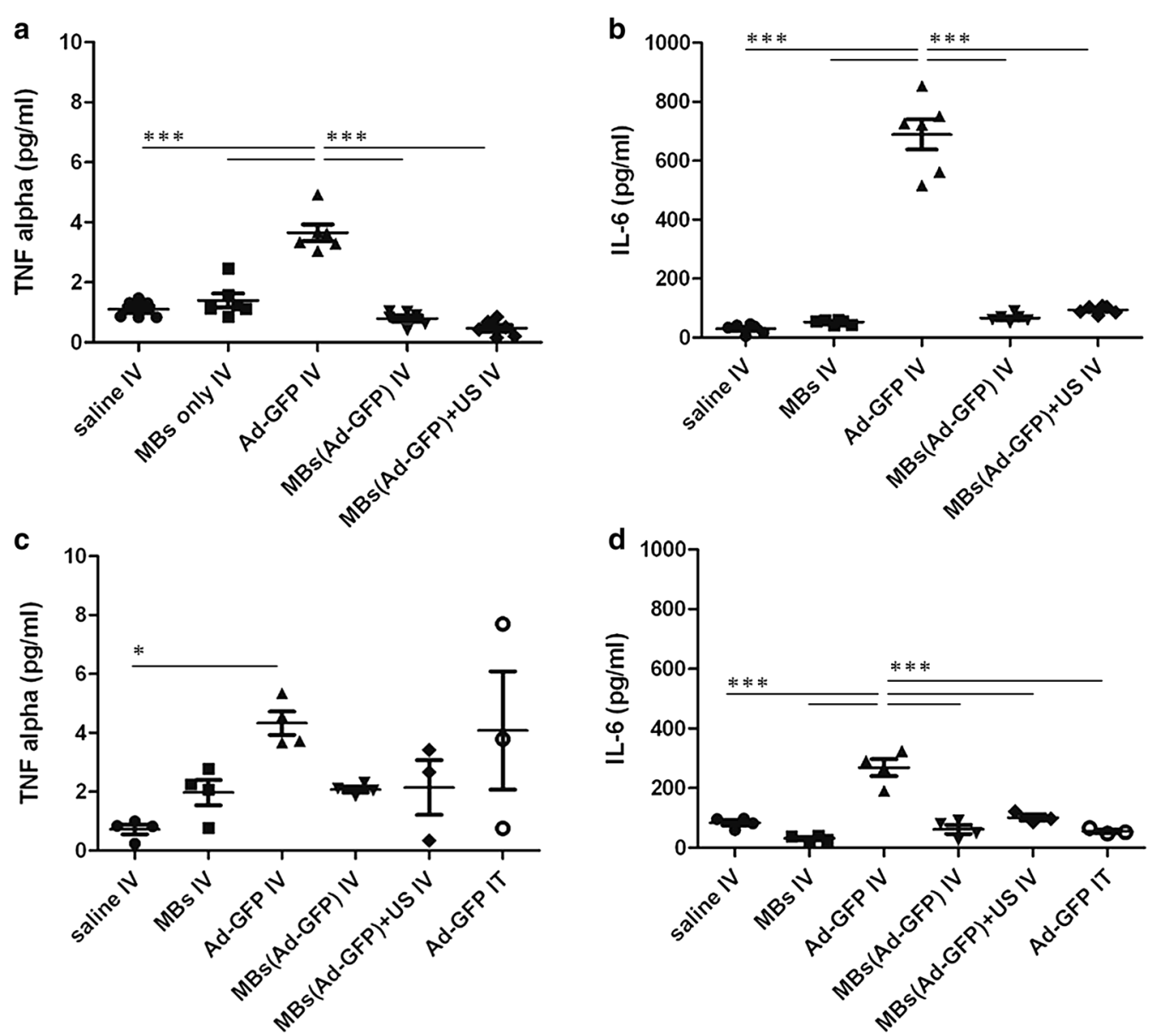

Fig. 5 Quantification of serum inflammatory cytokines. Innate immunity was evaluated by sandwich ELISA by quantifying serum cytokines TNF alpha a EXP.1, and c EXP.2, and serum IL-6 b EXP.1, and $\mathbf{d}$ EXP.2. Groups means are represented as horizontal bars (EXP.1 n=6 mice/group; XPp.2 $\mathrm{n}=4$ mice for saline IV, MBs IV, hAd-GFP IV, MBs(hAd-GFP) IV groups and $\mathrm{n}=3$ mice for MBs(hAd-GFP) + US IV and hAd-GFP IT. Data are analyzed by two way ANOVA and Tukey's post-test, ${ }^{*} p<0.05,{ }^{* * *} p<0.001$ )

\section{Discussion}

Prostate cancer is a very common cancer in men in the United States ranking as the third-leading cause of cancer death in men [31]. Primary prostate cancer can be treated successfully in many cases with surgical prostate resection, radiation, and hormonal therapy, with radiation therapy being used as the main choice for locally advanced prostate cancer. However despite receiving treatment, over a third of these patients will progress to an androgen-independent, radiation-resistant prostate cancer [32]. There is a need to develop more effective therapeutic approaches, and gene therapy represents a promising new treatment option. Therapeutic genes of choice include pro-apoptotic genes, tumor suppressor genes, antisense sequences for oncogenes, and antitumor DNA vaccines. Recent gene therapy clinical trials for prostate cancer have used Adenovirus as a highly efficient gene transducing tool [24]. Together with the Adeno-associated virus, adenoviral vectors belong to the category of the non-integrating vectors, they can be produced at a higher titer and display a robust expression of the therapeutic genes. These vectors can be easily engineered to make them safer and less immunogenic [33]. For example, the substitution of serotype 5 hexons with serotype 3 can protect adenovirus form inactivation by neutralizing antibody anti-hAd5 that are commonly circulating in patients due to preexisting immunization [34, 35]. In fact, the main challenges associated with the systemic delivery of adenoviral vector are not only the naive immune response but also the immunity to the virus serotype stemming from natural infection and liver toxicity [13].

Adenoviruses interact with the host cell and internalize using specific receptors. Adenovirus 5 is one of the main serotypes currently used in the clinics, and it employs 

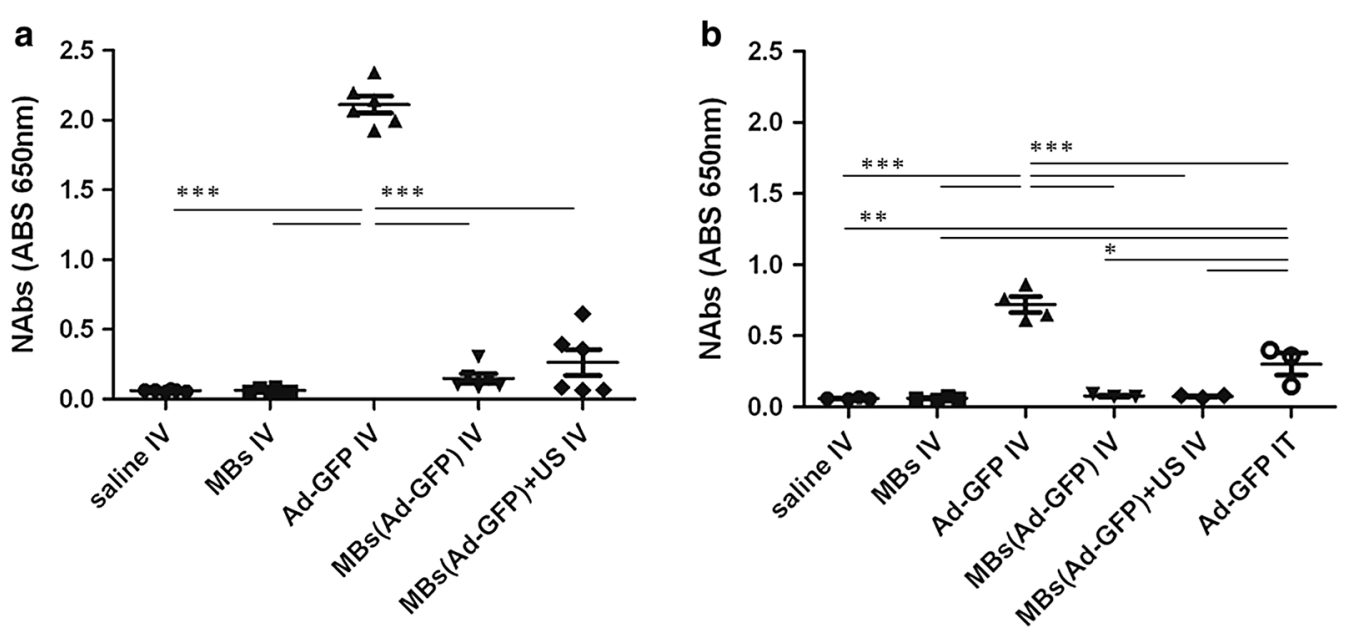

Fig. 6 Detection of serum neutralizing antibodies. Humoral response was determined by direct ELISA of serum NAbs (IgG anti-hAd), a Exp.1, b Exp.2. Group's means are represented as horizontal bars. (EXP.1 $n=6$ mice/group; EXP. $n=4$ mice for saline IV, MBs IV, hAd-GFP IV, MBs (hAd-GFP) IV groups and $n=3$ mice for MBs(hAd-GFP) + US IV and hAd-GFP IT. Data are analyzed by two way ANOVA and Tukey's post-test, ${ }^{*} p<0.05,{ }^{* *} p<0.01$, $\left.{ }^{* * *} p<0.001\right)$

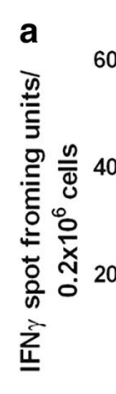
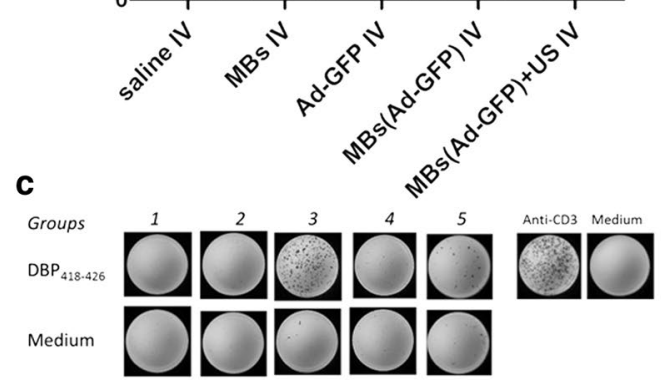

b
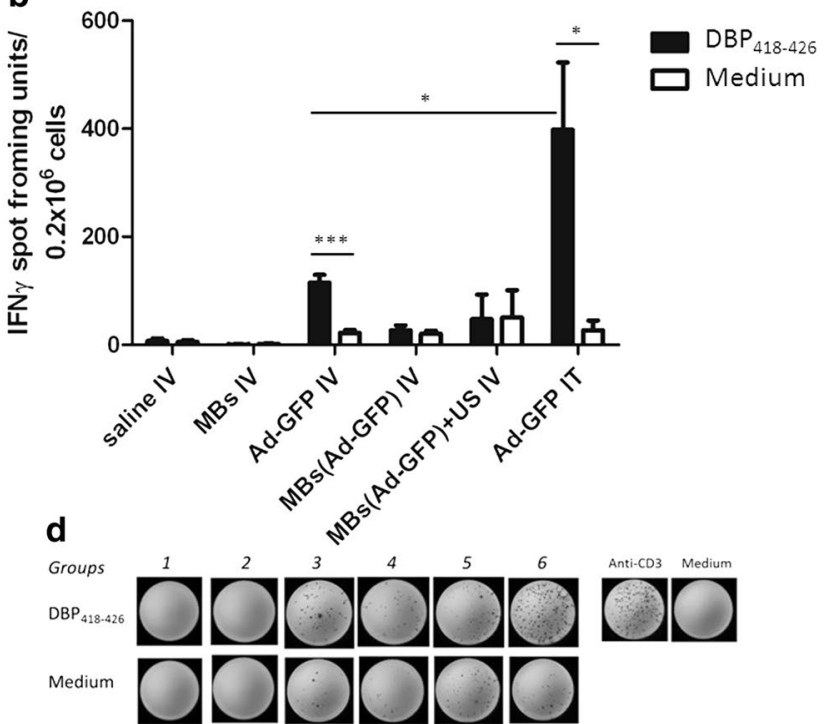

Fig. 7 Detection of INF- $\gamma$ producing $C D 8^{+}$T. Cellular response was assay by ELIspot counting the number of INF- $\gamma$ spots forming units after ex vivo stimulation of splenocytes with DBP ${ }_{418-426}$ peptide $\mathbf{a}, \mathbf{c}$ EXP.1, b, d EXP.2. Group means are represented as in the histograms. $\mathbf{c}, \mathbf{d}$ Exemplary samples. The nonspecific activator anti-CD3 antibody was used as positive control for the assay. (EXP.1 and EXP. $2 \mathrm{n}=3$ mice/group. Data are analyzed by multiple t-test of splenocytes from control and treated mice stimulated with media, spontaneous, or $\mathrm{DBP}_{418-426}$, stimulated, ${ }^{*} p<0.05$, ${ }^{* * *} p<0.001$ )

Coxsackie and Adenovirus Receptor (CAR) to adhere to target cells [36]. This receptor is expressed at low levels in primary tumors, including prostate cancer, when compared to established human cancer cell lines [37].

Infection and replication by human adenovirus has been thought to be restricted to human cells. Murine cells have been generally considered non-permissive, thereby limiting preclinical studies of gene transfer techniques [38]. However, here we showed that murine tissue could be transduced with hAds even if at a lower extent.

To overcome the aforementioned challenges through elicitation of the immune response and off-target viral distribution and expression, we have developed an imageguided gene transfer method (US Patent 8,454,937) 
utilizing a combination of lipid-encapsulated perfluorocarbon microbubbles (MBs) and ultrasonic waves (US) to enclose and protect hAds from the immune system to deliver the adenoviruses to a site-specific tissue bypassing the requirement of specific receptors [21, 25-27]. We have previously shown in immune compromised mice that this innovative gene transfer system can be used to specifically deliver hAd-GFP to a prostate tumor xenograft after systemic injection of the virus [25]. We demonstrated, by delivering a replication-deficient or a conditionally replication-competent adenovirus expressing the pro-apoptotic gene mda7/interleukin-24 enclosed in microbubble and in combination with ultrasound, that we could achieve sustained expression of the transgene in the sonoporated region and induce a reduction or complete eradication of a human prostate tumor xenograft [21]. Using this microbubble gene transfer method we were also able to radio-sensitize and reduce the tumor burden of a tumor xenograft of the prostate cell line DU145 by delivering replication-deficient human adenovirus expressing the tumor suppressor genes p53, and $\mathrm{pRb}$ [27]. Moreover, we confirmed our previously published data, showing that after reconstitution of microbubbles in the presence of adenovirus, the microbubbles need to be treated with human complement in order to inactivate any adenovirus loosely attached or included within the lipid shell and to achieve specific delivery of the hAds. The complement-treated microbubble-encapsulated adenovirus can be systemically injected intravenously into an immunocompetent C57BL/6 mouse without eliciting any innate immune response when compared to non-treated microbubbles or not protected adenovirus [24, 25].

The validity of our established image-guided gene therapy method has been confirmed by an independent laboratory that is using ultrasound-targeted microbubble (MB)-destruction to deliver conditionally replicationcompetent oncolytic adenoviruses that simultaneously produce a systemically active cancer-specific therapeutic cytokine [39] in prostate cancer.

The aim of the present study was to test if the microbubble/US system we have established [21, 24, 25, 27] could efficiently deliver human adenoviruses to a targeted diseased tissue protecting the virus from the innate and adaptive immunity using immunocompetent TRAMPC2 mice (C57BL/6 background) as pre-clinical prostate cancer model.

Using an in vitro model, we compared the transduction efficiency of the hAd-GFP in the mouse TRAMP-C2 and human DU145 prostate cancer cell lines and found that the pattern of expression of the CAR receptors and integrins $\alpha_{\mathrm{V}} \beta_{5}$ and $\alpha_{\mathrm{V}} \beta_{3}$, all required for the adhesion and internalization of the adenovirus by the host cells, was comparable. However, notwithstanding this similarity, we observed a pronounced reduction in the uptake of the virus when comparing murine cells and human prostate cell line. This can be explained by the high sequence homology in the extracellular domain of CAR from human and mice $[40,41]$ and CAR-independent pathways for cell transduction [42]. However, we detected a dose-dependent increase of the GFP positive cells in both cell lines $24 \mathrm{~h}$ post-infection. Finally, and more relevant for the general purpose of our study, we showed that both mouse TRAMP-C2 and human DU145 prostate cancer cell lines were able to support an efficient expression of the GFP transgene regulated by the strong CMV promoter at 48 and $72 \mathrm{~h}$ post-transfection.

The second goal of this study was to test the ability of the microbubbles to protect the systemically delivered adenoviral vectors from the innate and adaptive immune system of an immunocompetent mouse in vivo, using our image-guided delivery system. For this purpose, we used the TRAMP-C2 model of prostate cancer. From the original TRAMP mouse, that spontaneously develops prostate cancer, several cell lines have been established, such as TRAMP-C1 and C2, and these can be used to establish syngeneic subcutaneous grafts in C57BL/6 mice [43]. In our study, we used healthy immunocompetent C57BL/6 mice and mice bearing a syngeneic TRAMP-C2 prostate tumor to better represent the immune response of cancer patients.

Adenoviruses are able to induce a strong inflammatory response, which at its first step involves the activation of NK, professional APC, neutrophils, the complement cascade and the secretion of cytokines [13]. Dendritic cells in the spleen have been demonstrated to be directly transduced by systemically administered adenovirus resulting in the induction of IL-6, IL-12, and other cytokines [44]. The administration of human adenoviral vectors in protocols of gene therapy can lead to side effects in patients such as liver toxicity, thrombocytopenia and acute inflammation [45]. In order to assess if the microbubbles could protect the hAds from the activation of the innate immunity following systemic delivery, we injected the hAds enclosed in microbubbles through the tail vein of the mice. Two hours after intravenous injection, corresponding to the previously reported median time of secretion peak for TNF- $\alpha$ and IL-6 in C57BL/6 mice [46$48]$, blood samples were collected from the treated mice and levels of cytokines in their serum were quantified. We observed that the microbubbles completely protected hAds from eliciting an immune response, as showed by the absence of inflammatory cytokines when compared to the expected and well-documented response obtained after injection of non-protected hAds [11, 13, $44,49,50]$. We did not observe any difference among 
ultrasound-treated and non-treated mice (EXP.1 to the right kidney, EXP.2 to the tumor on the right flank), confirming the high stability of the microbubbles used. Furthermore, we noticed a very low level or absence of virus leak when bubbles cavitation was induced by sonoporation. Mice that received an intratumoral injection of the hAds showed an increase of only TNF- $\alpha$ expression, which naturally precedes IL-6 $[46,48]$, suggesting that anatomical barriers such as the tight junction between tumor cells may have reduced the path of the viral vector delaying the elicitation of innate immunity.

The second barrier to viral infection is the adaptive immunity, which is comprised of activated $\mathrm{CD} 4^{+}, \mathrm{CD} 8^{+}$ $\mathrm{T}$ cells and antibody-secreting plasma cells [13]. During a scheduled treatment of cancer gene therapy, the real obstacle to effectively repeating systemic administrations of replication-deficient adenoviral vectors is the inactivation of the virus by complement proteins, preexisting anti-viral and neutralizing antibodies that can reduce the efficiency of transfection [11, 13]. In order to assess the activation of the adaptive immunity, at the experimental end point of 1 month from the last injection of microbubble encapsulated hAds either in combination with US or not, we measured the levels of serum IgG anti-adenovirus. We observed that the microbubbles completely protected hAds injected intravenously from eliciting a humoral response as shown by the absence of a statistically significant increase in secretion of antihAds antibodies. We could not detect differences among mice that received ultrasound treatment or not, confirming once again our previous observations. On the other hand, we detected a robust production of neutralizing antibodies in mice injected intravenously with unprotected hAds as observed by others [11,13]. Additionally, in mice injected intravenously with unprotected hAds, the relative number of neutralizing antibodies detected was twice as much in EXP.1 compared to EXP.2 due to the treatment schedule. Instead, intratumoral injection of hAds induced a lower titer of neutralizing antibody probably due to the target tissue characteristics and the route of administration.

To assess the activation of cell-mediated immunity, we investigated the incidence of antigen specific INF- $\gamma$ producing $\mathrm{CD}^{+} \mathrm{T}$ cells. The vector we used in our experiments is a 1st generation, E1 deleted adenovirus that still allows for the leaky late gene expression of some viral products including the nonstructural DNA Binding Protein (DBP). DBP contains a MHC-class I restricted epitope that have been shown to be a $\mathrm{CD} 8^{+}$principal epitope in C57BL/6 mice [30]. In order to detect the presence of DBP specific INF- $\gamma$ producing $\mathrm{CD}^{+} \mathrm{T}$ cells, we performed an INF- $\gamma$ ELIspot assay. We collected splenocytes at the experimental end points and stimulated them ex vivo with the DBP peptide and INF- $\gamma$ spot forming units were counted. We observed that the systemic injection of microbubble encapsulated hAd-GFP with or without the use of US treatment does not induce a statistically significant increase in the number of spots observed when compared to the spontaneous release of INF- $\gamma$ in both healthy mice (EXP.1) and mice bearing a prostate tumor (EXP.2). Conversely, we observed a strong activation of $\mathrm{CD}^{+} \mathrm{T}$ cells in the positive controls (IV and IT injections of naked hAds) and the highest count of INF- $\gamma$ spot forming units was detected after intratumoral injection of hAd-GFP confirming that the route of administration and viral dose administered may affect the type of immune response [30, 51, 52].

\section{Conclusions}

These results demonstrated that our MBs/US-guided gene delivery system can effectively protect a viral vector from the activation of both humoral and cellular immunity response. Also, our data provides evidence that the TRAMP-C2 mouse model of prostate cancer is a suitable system to study the feasibility of this novel image-guided gene transfer technique in immune competent animals offering the milestone and opportunity to further translate this ultrasound-mediated MBs/hAd delivery system from the bench to the bedside.

\section{Additional file}

Additional file 1: Figure S1. Virus Titration. Virus stocks used for the in vivo experiments were tittered infecting HEK-293 cells at six serial dilutions $\left(10^{-2}, 10^{-3}, 10^{-4}, 10^{-5}, 10^{-6}\right.$, and $\left.10^{-7}\right)$ of Ad-GFP. The TCID ${ }_{50}$ method was used to calculate the titer. Representative pictures are showed for each dilution tested and the control (only media). Figure S2. Enhancement of Human Adenoviral transduction efficiency in TRAMP-C2 and DU145 following US-mediated MBs(Ad) delivery system. TRAMP-C2 and DU145 cells were transduced with $10 \mathrm{MOI}$ of Ad-GFP or MBs(Ad-GFP)+US. Cells receiving MBs(Ad-GFP) were treated with US for 1 minute. 24 hours after infection, the percentage of cells transduced were determined by Flow Cytometry. Data are representative of three biological repeats, analyzed by Student T-test (Ad-GFP vs. MBs(Ad-GFP)+US). ${ }^{*} p<0.05,{ }^{* *} p<0.001$.

\section{Abbreviations}

APC: antigen presenting cell; CAR: Coxsackie and Adenovirus Receptor; CMV: cytomegalovirus; CTL: cytotoxic T lymphocyte; DBP: DNA binding protein; FBS: fetal bovine serum; GFP: green fluorescent protein; hAds: human adenovirus; IL-6: interleukin 6; IT: intratumoral; IV: intravenous; MBs: microbubbles; MFI: median fluorescence intensity; MOI: multiplicity of infection; NAbs: neutralizing antibodies; NK: natural killer; TNF-a: tumor necrosis factor a; US: ultrasound; UTMD: ultrasound targeted microbubbles destruction.

\section{Authors' contributions}

FDC conducted the research, analyzed, interpreted the data, and contributed to writing the manuscript. LT, BB conducted part of the research, analyzed and helped interpreting the data. ETV discussed the project, analyzed and help writing the manuscript. RN conducted part of the research and discussed the data. OB conducted part of the research and discussed the data. GDM discussed the project, analyzed and interpreted the data and helped writing the 
manuscript. PPC provided research material, discussed the project, analyzed and interpreted the data, and was a major contributor in writing the manuscript. CMH provided research material, discussed the project, analyzed and interpreted the data, and was a major contributor in writing the manuscript. All authors read and approved the final manuscript.

\section{Author details}

1 Department of BioMolecular Sciences, University of Mississippi, University, MS, USA. ${ }^{2}$ National Center for Natural Products Research, University of Mississippi, University, MS, USA. ${ }^{3}$ Department of Radiation Oncology, Medical Center Cancer Institute, Jackson, MS, USA. ${ }^{4}$ Department of Radiology, University of Mississippi Medical Center, Jackson, MS 39126, USA. ${ }^{5}$ Department of Biochemistry and Microbiology, Joan C. Edwards School of Medicine, Marshall University, Huntington, WV, USA. ${ }^{6}$ Division of Clinical Immunology and Allergy, Department of Medicine, University of Mississippi Medical Center, Jackson, MS, USA. ${ }^{7}$ Department of BioMolecular Sciences, Department of Radiation Oncology, University of Mississippi, Jackson, MS 39126, USA.

\section{Acknowledgements}

We gratefully acknowledge the University of Mississippi Department of BioMolecular Sciences, National Center for Natural Product Research, Radiation Oncology, and Radiology Departments for their support.

\section{Competing interests}

All authors have read the journal's policy on disclosure of potential competing interests and all the authors declare that they have no any financial or personal relationship with organizations that could potentially be perceived as influencing the described research.

\section{Availability of data and materials}

The datasets used and/or analyzed during the current study are available from the corresponding author on reasonable request.

\section{Consent for publication}

Not applicable.

\section{Ethics approval and consent to participate}

Not applicable.

\section{Funding}

The present studies were funded by a UMMC Intramural Grant (to CMH and PPC) and partially funded by NIH Grant CA138510-01 (to PPC). Candace M. Howard is partially supported by the National Institute of General Medical Sciences of the National Institutes of Health under Award Number 5U54GM115428. The content is solely the responsibility of the authors and does not necessarily represent the official views of the National Institutes of Health. All authors have read the journal's policy on disclosure of potential conflict of interest and all the authors declare that they have no any financial or personal relationship with organizations that could potentially be perceived as influencing the described research.

\section{Publisher's Note}

Springer Nature remains neutral with regard to jurisdictional claims in published maps and institutional affiliations.

Received: 21 September 2018 Accepted: 2 January 2019

Published online: 11 January 2019

\section{References}

1. Chen GX, Zhang S, He XH, Liu SY, Ma C, Zou XP. Clinical utility of recombinant adenoviral human p53 gene therapy: current perspectives. OncoTargets Ther. 2014;7:1901-9.

2. Appaiahgari MB, Vrati S. Adenoviruses as gene/vaccine delivery vectors: promises and pitfalls. Expert Opin Biol Ther. 2015;15(3):337-51.

3. Castro MG, Candolfi M, Wilson TJ, Calinescu A, Paran C, Kamran N, et al. Adenoviral vector-mediated gene therapy for gliomas: coming of age. Expert Opin Biol Ther. 2014;14(9):1241-57.
4. Volpers C, Kochanek S. Adenoviral vectors for gene transfer and therapy. J Gene Med. 2004;6(Suppl 1):S164-71.

5. Bergelson JM, Cunningham JA, Droguett G, Kurt-Jones EA, Krithivas A, Hong JS, et al. Isolation of a common receptor for Coxsackie B viruses and adenoviruses 2 and 5. Science. 1997;275(5304):1320-3.

6. Yuan ZY, Guan ZZ, Zhang L, Xu RH. Effect of expression of coxsackie and adenovirus receptor on antitumor activity of genetically modified adenovirus. Ai Zheng. 2005;24(4):502-5.

7. Ganly I, Mautner V, Balmain A. Productive replication of human adenoviruses in mouse epidermal cells. J Virol. 2000;74(6):2895-9.

8. Hallden G, Hill R, Wang Y, Anand A, Liu TC, Lemoine NR, et al. Novel immunocompetent murine tumor models for the assessment of replicationcompetent oncolytic adenovirus efficacy. Mol Ther. 2003;8(3):412-24.

9. Zhu J, Huang $X$, Yang $Y$. Innate immune response to adenoviral vectors is mediated by both Toll-like receptor-dependent and -independent pathways. J Virol. 2007:81(7):3170-80.

10. Zhu J, Martinez J, Huang $X$, Yang $Y$. Innate immunity against vaccinia virus is mediated by TLR2 and requires TLR-independent production of IFNbeta. Blood. 2007;109(2):619-25.

11. Nayak S, Herzog RW. Progress and prospects: immune responses to viral vectors. Gene Ther. 2010;17(3):295-304.

12. Bradley RR, Lynch DM, lampietro MJ, Borducchi EN, Barouch DH. Adenovirus serotype 5 neutralizing antibodies target both hexon and fiber following vaccination and natural infection. J Virol. 2012;86(1):625-9.

13. Jooss K, Chirmule N. Immunity to adenovirus and adeno-associated viral vectors: implications for gene therapy. Gene Ther. 2003;10(11):955-63.

14. Khare R, Chen CY, Weaver EA, Barry MA. Advances and future challenges in adenoviral vector pharmacology and targeting. Curr Gene Ther. 2011;11(4):241-58

15. Waddington SN, McVey JH, Bhella D, Parker AL, Barker K, Atoda H, et al. Adenovirus serotype 5 hexon mediates liver gene transfer. Cell. 2008;132(3):397-409.

16. Xu Z, Qiu Q, Tian J, Smith JS, Conenello GM, Morita T, et al. Coagulation factor $X$ shields adenovirus type 5 from attack by natural antibodies and complement. Nat Med. 2013;19(4):452-7.

17. Carlisle RC, Di Y, Cerny AM, Sonnen AF, Sim RB, Green NK, et al. Human erythrocytes bind and inactivate type 5 adenovirus by presenting Coxsackie virus-adenovirus receptor and complement receptor 1. Blood. 2009;113(9):1909-18.

18. Lyons M, Onion D, Green NK, Aslan K, Rajaratnam R, Bazan-Peregrino M, et al. Adenovirus type 5 interactions with human blood cells may compromise systemic delivery. Mol Ther. 2006;14(1):118-28.

19. Wisse E, Jacobs F, Topal B, Frederik P, De Geest B. The size of endothelial fenestrae in human liver sinusoids: implications for hepatocyte-directed gene transfer. Gene Ther. 2008;15(17):1193-9.

20. AuT, Thorne S, Korn WM, Sze D, Kirn D, Reid TR. Minimal hepatic toxicity of Onyx-015: spatial restriction of coxsackie-adenoviral receptor in normal liver. Cancer Gene Ther. 2007;14(2):139-50.

21. Greco A, Di Benedetto A, Howard CM, Kelly S, Nande R, Dementieva $Y$, et al. Eradication of therapy-resistant human prostate tumors using an ultrasound-guided site-specific cancer terminator virus delivery approach. Mol Ther. 2010;18(2):295-306.

22. Goldberg BB, Liu JB, Forsberg F. Ultrasound contrast agents: a review. Ultrasound Med Biol. 1994;20(4):319-33.

23. Howard CM. The role of ultrasound contrast agents in gene therapy. Appl Radiol. 2004;33(suppl):126-35.

24. Dash R, Azab B, Shen XN, Sokhi UK, Sarkar S, Su ZZ, et al. Developing an effective gene therapy for prostate cancer: new technologies with potential to translate from the laboratory into the clinic. Discov Med. 2011;11(56):46-56.

25. Howard CM, Forsberg F, Minimo C, Liu JB, Merton DA, Claudio PP. Ultrasound guided site specific gene delivery system using adenoviral vectors and commercial ultrasound contrast agents. J Cell Physiol. 2006;209(2):413-21.

26. Nande R, Claudio P. Ultrasound contrast agents in cancer therap. In: Claudio PP, Vogiatzi P, editors. Cutting edge therapies for cancer in the 21st century. Soest: Bentham Science Publishers; 2014. p. 425-512.

27. Nande R, Greco A, Gossman MS, Lopez JP, Claudio L, Salvatore M, et al. Microbubble-assisted p53, RB, and p130 gene transfer in combination with radiation therapy in prostate cancer. Curr Gene Ther. 2013;13(3):163-74. 
28. Claudio PP, Fratta L, Farina F, Howard CM, Stassi G, Numata S, et al. Adenoviral RB2/p130 gene transfer inhibits smooth muscle cell proliferation and prevents restenosis after angioplasty. Circ Res. 1999;85(11):1032-9.

29. Nande R, Di Benedetto A, Aimola P, De Carlo F, Carper M, Claudio CD, et al. Targeting a newly established spontaneous feline fibrosarcoma cell line by gene transfer. PLOS ONE. 2012;7(5):e37743.

30. McKelvey T, Tang A, Bett AJ, Casimiro DR, Chastain M. T-cell response to adenovirus hexon and DNA-binding protein in mice. Gene Ther. 2004:11(9):791-6.

31. Siegel RL, Miller KD, Jemal A. Cancer statistics, 2017. CA Cancer J Clin. 2017:67(1):7-30.

32. Vogiatzi P, Cassone M, Claudio L, Claudio PP. Targeted therapy for advanced prostate cancer: looking through new lenses. Drug News Perspect. 2009:22(10):593-601.

33. Das SK, Menezes ME, Bhatia S, Wang XY, Emdad L, Sarkar D, et al. Gene therapies for cancer: strategies, challenges and successes. J Cell Physiol. 2015;230(2):259-71.

34. Abe S, Okuda K, Ura T, Kondo A, Yoshida A, Yoshizaki S, et al. Adenovirus type 5 with modified hexons induces robust transgene-specific immune responses in mice with pre-existing immunity against adenovirus type 5 . J Gene Med. 2009;11(7):570-9.

35. Short JJ, Rivera AA, Wu H, Walter MR, Yamamoto M, Mathis JM, et al. Substitution of adenovirus serotype 3 hexon onto a serotype 5 oncolytic adenovirus reduces factor $\mathrm{X}$ binding, decreases liver tropism, and improves antitumor efficacy. Mol Cancer Ther. 2010;9(9):2536-44.

36. Philipson L, Pettersson RF. The coxsackie-adenovirus receptor-a new receptor in the immunoglobulin family involved in cell adhesion. Curr Top Microbiol Immunol. 2004;273:87-111.

37. Glasgow JN, Bauerschmitz GJ, Curiel DT, Hemminki A. Transductional and transcriptional targeting of adenovirus for clinical applications. Curr Gene Ther. 2004;4(1):1-14.

38. Jogler C, Hoffmann D, Theegarten D, Grunwald T, Uberla K, Wildner O. Replication properties of human adenovirus in vivo and in cultures of primary cells from different animal species. J Virol. 2006;80(7):3549-58.

39. Sarkar S, Quinn BA, Shen XN, Dash R, Das SK, Emdad L, et al. Therapy of prostate cancer using a novel cancer terminator virus and a small molecule BH-3 mimetic. Oncotarget. 2015;6(13):10712-27.

40. Fechner $\mathrm{H}$, Haack $\mathrm{A}$, Wang $\mathrm{H}$, Wang $\mathrm{X}$, Eizema K, Pauschinger $\mathrm{M}$, et al. Expression of coxsackie adenovirus receptor and alphav-integrin does not correlate with adenovector targeting in vivo indicating anatomical vector barriers. Gene Ther. 1999;6(9):1520-35.
41. Tomko RP, Xu R, Philipson L. HCAR and MCAR: the human and mouse cellular receptors for subgroup $C$ adenoviruses and group B coxsackieviruses. Proc Natl Acad Sci USA. 1997:94(7):3352-6.

42. Hidaka C, Milano E, Leopold PL, Bergelson JM, Hackett NR, Finberg RW, et al. CAR-dependent and CAR-independent pathways of adenovirus vector-mediated gene transfer and expression in human fibroblasts. J Clin Invest. 1999:103(4):579-87.

43. Greenberg NM, DeMayo F, Finegold MJ, Medina D, Tilley WD, Aspinall JO, et al. Prostate cancer in a transgenic mouse. Proc Natl Acad Sci USA. 1995:92(8):3439-43.

44. Yamaguchi T, Kawabata K, Koizumi N, Sakurai F, Nakashima K, Sakurai H, et al. Role of MyD88 and TLR9 in the innate immune response elicited by serotype 5 adenoviral vectors. Hum Gene Ther. 2007;18(8):753-62.

45. Seiler MP, Cerullo V, Lee B. Immune response to helper dependent adenoviral mediated liver gene therapy: challenges and prospects. Curr Gene Ther. 2007;7(5):297-305

46. Smith SR, Calzetta A, Bankowski J, Kenworthy-Bott L, Terminelli C. Lipopolysaccharide-induced cytokine production and mortality in mice treated with Corynebacterium parvum. J Leukoc Biol. 1993;54(1):23-9.

47. Copeland S, Warren HS, Lowry SF, Calvano SE, Remick D, Inflammation, et al. Acute inflammatory response to endotoxin in mice and humans. Clin Diagn Lab Immunol. 2005;12(1):60-7.

48. Blanque R, Meakin C, Millet S, Gardner CR. Hypothermia as an indicator of the acute effects of lipopolysaccharides: comparison with serum levels of IL1 beta, IL6 and TNF alpha. Gen Pharmacol. 1996;27(6):973-7.

49. Manickan E, Smith JS, Tian J, Eggerman TL, Lozier JN, Muller J, et al. Rapid Kupffer cell death after intravenous injection of adenovirus vectors. Mol Ther. 2006;13(1):108-17

50. Hartman ZC, Appledorn DM, Amalfitano A. Adenovirus vector induced innate immune responses: impact upon efficacy and toxicity in gene therapy and vaccine applications. Virus Res. 2008;132(1-2):1-14.

51. Christ M, Lusky M, Stoeckel F, Dreyer D, Dieterle A, Michou Al, et al. Gene therapy with recombinant adenovirus vectors: evaluation of the host immune response. Immunol Lett. 1997;57(1-3):19-25.

52. Ren Z, Ye X, Fang C, Lu Q, Zhao Y, Liu F, et al. Intratumor injection of oncolytic adenovirus expressing HSP70 prolonged survival in melanoma B16 bearing mice by enhanced immune response. Cancer Biol Ther. 2008:7(2):191-5.
Ready to submit your research? Choose BMC and benefit from:

- fast, convenient online submission

- thorough peer review by experienced researchers in your field

- rapid publication on acceptance

- support for research data, including large and complex data types

- gold Open Access which fosters wider collaboration and increased citations

- maximum visibility for your research: over $100 \mathrm{M}$ website views per year

At $\mathrm{BMC}$, research is always in progress.

Learn more biomedcentral.com/submissions 